\title{
EVALUASI PENGGUNAAN OBAT PADA PASIEN HIPERTENSI RAWAT JALAN DI RUMAH SAKIT UMUM WISMA RINI PRINGSEWU TAHUN 2019
}

\section{DRUG USE EVALUATION IN HYPERTENSION OUTPATIENT AT WISMA RINI GENERAL HOSPITAL PRINGSEWU IN 2019}

\author{
Ramadhan Triyadi ${ }^{1}$, Akhmad Rokiban ${ }^{2}$, Anggun Carima ${ }^{3}$ \\ ${ }^{1}$ Fakultas Kedokteran Program Studi Farmasi Universitas Lampung \\ ${ }^{2}$ Fakultas MIPA, Jurusan Farmasi Universitas Tulang Bawang Lampung \\ Email: ramadhantriyandi0101@fk.unila.ac.id \\ HP. 0812-7342-4287
}

\begin{abstract}
Hypertension is a non-communicable disease characterized by the increase of systolic blood pressure is $>140 \mathrm{mmHg}$ and diastolic blood pressure is $>90 \mathrm{mmHg}$. Hypertension is also the major risk factor of other cardiovascular disease. The incidence rate of hypertension with or without complications increases every year, so the potential for inaccurate use of drugs is increasing. The purpose of this research is to determine the characteristics of hypertension outpatients and the proper hypertension drug use in hypertension outpatients at Wisma Rini General Hospital Pringsemu in 2019 based on the proper patient, the proper indication, the proper drug, and the proper dose using the standard reference of Guidelines JNC VIII. This research is descriptive research, the data was collected retrospectively based on medical records. The sample collection technique in this research is using a purposive sampling technique. The results in this study obtained from 110 patient samples diagnosed with the hypertension showed that most of hypertension patients are women $(55,46 \%)$, mostly aged 56-65 years old (40\%), and the most taken hypertension drug is CCB group amlodipine with 78 patients (71\%). The evaluation of antihypertensive drug use obtained is proper patient with 110 patients (100\%), proper indication with 110 patients (100\%), proper drug with 92 patients (75,6\%), and proper dose with 110 patients (100\%).
\end{abstract}

Keywords: Antihypertensive, Hypertension, Accuracy drug use.

\begin{abstract}
Abstrak
Hipertensi merupakan salah satu penyakit tidak menular yang ditandai dengan peningkatan tekanan darah sistolik $>140 \mathrm{mmHg}$ dan tekanan darah diastolik $>90$ $\mathrm{mmHg}$. Hipertensi juga menjadi faktor risiko utama penyakit kardiovaskuler lainnya. Angka kejadian hipertensi dengan atau tanpa komplikasi meningkat tiap tahunnya, sehingga potensi adanya ketidaktepatan penggunaan obat semakin meningkat. Tujuan dari penelitian ini untuk mengetahui karakteristik pasien hipertensi dan ketepatan penggunaan obat hipertensi pada pasien hipertensi rawat jalan di RSU Wisma Rini Pringsewu tahun 2019 berdasarkan tepat pasien, tepat indikasi, tepat obat, dan tepat dosis dengan menggunakan standar acuan Guidelines JNC VIII. Penelitian ini
\end{abstract}


merupakan penelitian secara deskriptif dengan pengambilan data rekam medik secara retrospektif. Teknik pengambilan sampel pada penelitian ini menggunakan teknik purposive sampling. Hasil penelitian yang diperoleh dari 110 sampel pasien dengan diagnosa hipertensi menunjukan bahwa penderita hipertensi paling banyak adalah perempuan $(55,46 \%)$, paling banyak usia 56-65 tahun $(40 \%)$ dan penggunaan obat hipertensi paling banyak yaitu amlodipin golongan CCB sebanyak 78 pasien (71\%). Evaluasi penggunaan obat antihipertensi diperoleh yaitu tepat pasien sebanyak 110 pasien $(100 \%)$, tepat indikasi sebanyak 110 pasien $(100 \%)$, tepat obat sebanyak 92 pasien $(75,6 \%)$, dan tepat dosis sebanyak 110 pasien $(100 \%)$.

Kata Kunci : Antihipertensi, Hipertensi, Ketepatan penggunaan obat.

\section{PENDAHULUAN}

Hipertensi atau penyakit tekanan darah tinggi adalah suatu keadaan kronis yang ditandai dengan meningkatnya tekanan darah pada dinding pembuluh darah arteri.

Evaluasi penggunaan obat hipertensi bertujuan untuk menjamin penggunaan obat yang rasional pada penderita hipertensi. Penggunaan obat yang rasional sangat penting untuk meningkatkan keberhasilan terapi..

Dari data WHO (World Health Organization), menunjukan bahwa di dunia jumlah orang dewasa dengan hipertensi meningkat dari 594 juta pada tahun 1975 menjadi 1,13 miliar pada tahun 2015. Riset Kesehatan Dasar (Riskesdas) pada tahun 2018 menunjukan bahwa penderita hipertensi mencapai $34,1 \%$ dari jumlah penduduk Indonesia dan mengalami kenaikan dari tahun 2013 sebanyak 25,8\%. Pusat Data dan Informasi Kesehatan Provinsi Lampung menyatakan bahwa prevalensi hipertensi di Lampung berdasarkan diagnosis tenaga kesehatan di Indonesia tahun 2013 mencapai 7,4\% dan menempati urutan ke tiga dalam jumlah kasus 10 penyakit terbanyak di Provinsi Lampung pada tahun 2015
Berdasarkan pra-penelitian yang telah peneliti lakukan di Rumah Sakit Umum Wisma Rini Pringsewu diperoleh data penyakit hipertensi termasuk kedalam 10 besar penyakit terbanyak di RSU Wisma Rini Pringsewu pada tahun 2019 dengan jumlah pasien 151 orang. Atas dasar informasi yang didapatkan dari berbagai literatur peneliti melakukan penelitian tentang Evaluasi Penggunaan Obat Hipertensi Pada Pasien Hipertensi di Rumah Sakit Wisma Rini Pringsewu Kabupaten Pringsewu.

\section{METODE PENELITIAN}

Penelitian ini merupakan penelitian non eksperimental dengan rancangan deskriptif yang menggunakan pendekatan secara retrospektif, yaitu suatu metode pengambilan data yang berhubungan dengan masa lampau. Pada penelitian ini dilakukan evaluasi mengenai penggunaan obat hipertensi berdasarkan parameter tepat pasien, tepat indikasi, tepat obat dan tepat dosis.

\section{Lokasi dan Waktu Penelitian}

Penelitian ini dilaksanakan di Penelitian ini dilakukan di Rumah Sakit Wisma Rini Pringsewu periode tahun 2019.

\section{Populasi Dan Sampel}

Populasi dalam penelitian ini adalah semua pasien terdiagnosa hipertensi 
di poli rawat jalan Rumah Sakit Wisma Rini Pringsewu periode tahun 2019.

Sampel dalam penelitian ini adalahpasien yang terdiagnosa Hipertensi di poli rawat jalan Rumah Sakit Wisma Rini Pringsewu periode tahun 2019 yang memenuhi kriteria inklusi, yaitu kriteria dimana subjek penelitian dapat mewakili dalam sampel penelitian yang memenuhi syarat sebagai sampel.

Penelitian yang dianalisis secara secara purposive sampling (non random sampling) yaitu pengambilan sampel secara purposive di dasarkan pada suatu pertimbangan tertentu yang dibuat oleh peneliti sendiri, berdasarkan ciri dan sifatsifat populasi yang sudah di ketahui sebelumnya.

Teknik purposive sampling dipilih karena keterbatasan jumlah rekam medis pasien Hipertensi selama periode tahun 2019. Rumus perhitungan sampel yaitu:

$$
\mathrm{n}=\frac{\mathrm{N}}{1+\mathrm{N}(\mathrm{d})^{2}}
$$

Keterangan :

n : besar sampel

$\mathrm{N} \quad$ : besar populasi

d : tingkat kepercayaan/ketepatan yang diinginkan $(0,05)$

Misal, besar populasi Pasien Hipertensi Rawat Jalan di Wisma Rini Pringsewu pada tahun 2019 sebanyak 151 pasien, maka perhitungan besar sampelnya adalah:

$$
\begin{array}{r}
\mathrm{n}=\frac{\mathrm{N}}{1+\mathrm{N}(\mathrm{d})^{2}} \\
\mathrm{n}=\frac{151}{1+151(0.05)^{2}} \\
\mathrm{n}=\frac{151}{1+151(0,0025)} \\
\mathrm{n}=110 \text { pasien }
\end{array}
$$

\section{Instrumen dan Pengolahan Data}

Bahan yang digunakan dalam penelitian ini adalah obat antihipertensi yang digunakan pasien hipertensi rawat jalan Rumah Sakit Wisma Rini Pringsewu tahun 2019. Alat yang digunakan dalam penelitian ini adalah seluruh rekam medis pasien hipertensi rawat jalan di Rumah Sakit Wisma Rini Pringsewu tahun 2019. Alat yang digunakan dalam penelitian ini adalah seluruh rekam medis pasien hipertensi rawat jalan di Rumah Sakit Wisma Rini Pringsewu tahun 2019

Analisis data yang dilakukan dalam penelitian ini yaitu Analisa Univariat (Analisa Deskriptif) yang bertujuan untuk menjelaskan atau mendeskripsikan katakteristik setiap variabel penelitian. Data yang diperoleh disajikan dalam bentuk persentase dalam tabel, kemudian diambil kesimpulan dari data yang disajikan tersebut. Pengolahan data dilakukan secara komputerisasi menggunakan program Microsoft word 2013.

\section{HASIL DAN PEMBAHASAN}

Berdasarkan hasil penelitian yang telah dilakukan, peneliti menggunakan responden berjumlah 110 yang sesuai dengan inklusi. 


\section{A. Analisis Univariat}

\section{Karakteristik Responden}

Tabel 1. Karakteristik Responden

\begin{tabular}{|c|c|c|}
\hline \multirow{2}{*}{$\begin{array}{c}\text { Karakteristik } \\
\text { Responden }\end{array}$} & \multicolumn{2}{|c|}{ Frekuensi } \\
\cline { 2 - 3 } & Jumlah & Persentase \\
\hline Perempuan & 61 & $55,46 \%$ \\
Laki-laki & 49 & $44,54 \%$ \\
\hline $17-25$ & 0 & $0 \%$ \\
$26-35$ & 7 & $6,37 \%$ \\
$36-45$ & 6 & $5,45 \%$ \\
$46-55$ & 20 & $18,18 \%$ \\
$56-65$ & 44 & $40 \%$ \\
$>65$ & 33 & $30 \%$ \\
\hline
\end{tabular}

Berdasarkan pada hasil penelitian di atas yang dilakukan di RSU Wisma Rini Pringsewu, diperoleh bahwa pasien hipertensi berjenis kelamin laki-laki sebanyak 49 penderita $(55,46 \%)$ dan pada perempuan sebanyak 61 penderita $(55,46 \%)$.

Temuan ini sesuai dengan penelitian sebelumnya yang dilakukan oleh Laura di Puskesmas Ikur Koto Kota Padang tahun 2018 menunjukan bahwa mayoritas penderita hipertensi adalah pasien perempuan yaitu sebanyak 25 penderita $(64,1 \%)$ dari 39 pasien

Berdasarkan pada hasil penelitian di atas yang dilakukan di RSU Wisma Rini Pringsewu, diperoleh kelompok umur 26 35 tahun sebanyak 7 penderita $(6,37 \%)$, kelompok umur 36 - 45 tahun sebanyak 6 penderita $(5,45 \%)$, kelompok umur 46 55 tahun sebanyak 20 penderita $(18,18 \%)$, kelompok umur $56-65$ tahun sebanyak 44 penderita (40\%) dan kelompok umur >65 sebanyak 33 penderita (30\%). Menurut hasil data tersebut, kasus hipertensi berdasarkan usia lebih banyak terjadi pada rentang usia 56-65 tahun sebesar $40 \%$.

Temuan ini sesuai dengan Penelitian yang dilakukan sebelumnya oleh Eka Kartika Untari dan teman-teman pada tahun 2015 di Puskesmas Siantan Hilir Kota Pontianak diperoleh hasil responden dengan mayoritas penderita hipertensi pada usia 56-65 tahun sebanyak 55,44\% dari 92 pasien (9).

\section{Karakteristik Berdasarkan Tingkat Hipertensi}

Tabel 2. Karakteristik Tingkat Hipertensi

\begin{tabular}{|c|c|c|}
\hline $\begin{array}{c}\text { Tingkatan } \\
\text { Hipertensi }\end{array}$ & $\begin{array}{c}\text { Jumlah } \\
\text { pasien }\end{array}$ & Presentase \\
\hline $\begin{array}{c}\text { Hipertensi } \\
\text { tingkat 1 }\end{array}$ & 72 & $65,45 \%$ \\
\hline $\begin{array}{c}\text { Hipertensi } \\
\text { tingkat 2 }\end{array}$ & 38 & 34,55 \\
\hline Total & $\mathbf{1 1 0}$ & $\mathbf{1 0 0 \%}$ \\
\hline
\end{tabular}

Dari hasil penelitian didapatkan bahwa pasien hipertensi rawat jalan di RS Wisma Rini Pringsewu periode 2019 paling banyak adalah hipertensi tingkat 1 sebanyak 72 penderita $(65,45 \%)$ dan hipertensi tingkat 2 sebanyak 38 penderita $(34,55 \%)$.

Hasil ini diperkuat dengan penelitian yang dilakukan sebelumnya di RSUP Prof. Dr. R. D Kondou Manado yang menunjukan bahwa pasien hipertensi yang paling banyak adalah hipertensi tingkat I sebanyak 31 penderita $(79,49 \%)$ dari 39 pasien. 


\section{B. Distribusi Pola Penggunaan Obat Hipertensi}

Distribusi pola penggunaan obat bertujuan untuk mengetahui obat apa saja yang digunakan oleh pasien hipertensi di RSU Wisma Rini Pringsewu. Berikut data hasil penelitian distribusi pola penggunaan obat hipertensi pada pasien hipertensi dapat di lihat pada tabel berikut

Tabel 3. Pola Penggunaan Obat Hipertensi

\begin{tabular}{|c|c|c|c|}
\hline $\begin{array}{l}\mathbf{N} \\
\mathbf{0} .\end{array}$ & Antihipertensi & $\begin{array}{l}\text { Jum } \\
\text { lah } \\
\text { pasi } \\
\text { en }\end{array}$ & $\begin{array}{c}\text { Persent } \\
\text { ase }\end{array}$ \\
\hline 1. & Monoterapi & 90 & $82 \%$ \\
\hline 2. & Kombinasi & 20 & $18 \%$ \\
\hline \multicolumn{2}{|r|}{ Total } & 110 & $100 \%$ \\
\hline 1. & Amlodipin & 78 & $71 \%$ \\
\hline 2. & Captopril & 12 & $11 \%$ \\
\hline 3. & $\begin{array}{c}\text { Amlodipin + } \\
\text { Captopril }\end{array}$ & 11 & $10 \%$ \\
\hline 4. & $\begin{array}{l}\text { Amlodipin+Fur } \\
\text { osemide }\end{array}$ & 1 & $1 \%$ \\
\hline 5. & $\begin{array}{c}\text { Amlodipin+Ca } \\
\text { ndesartan }\end{array}$ & 8 & $7 \%$ \\
\hline & Total & 110 & $100 \%$ \\
\hline
\end{tabular}

Berdasarkan hasil penelitian di atas, menunjukan bahwa pasien lebih banyak mendapatkan terapi antihipertensi satu obat yaitu monoterapi sebanyak 90 pasien (82\%) dan terapi kombinasi sebanyak 20 pasien (18\%).

Hasil ini diperkuat dengan penelitian yang dilakukan sebelumnya oleh Pande Mande di RSUP Prof. Dr. R. D Kondou Manado menunjukan bahwa pasien yang mendapatkan terapi hipertensi tunggal yaitu golongan CCB (amlodipin) paling banyak digunakan yaitu $(51,28 \%)$ dan kombinasi obat yang paling banyak digunakan adalah kombinasi $\beta$ blocker dan $\mathrm{CCB}, \mathrm{ACEI}$ dan $\beta$ blocker sebanyak $(5,13 \%)$.

\section{Evaluasi Ketepatan Penggunaan Obat Antihipertensi}

Evaluasi ketepatan penggunaan obat hipertensi dilakukan terhadap 110 data rekam medik pasien yang menderita hipertensi di instalasi rawat jalan di RSU Wisma Rini Pringsewu Tahun 2019. Evaluasi ketepatan dilakukan berdasarkan kriteria ketepatan, yaitu tepat pasien, tepat indikasi, tepat obat, dan tepat dosis.

\section{Tepat Pasien}

Evaluasi ketepatan pasien pada penggunaan obat hipertensi dilakukan dengan membandingkan riwayat alergi dan kontraindikasi obat yang diberikan dengan kondisi pasien pada data rekam medik.

Tabel 4. Ketepatan Pasien

\begin{tabular}{|l|c|c|}
\hline $\begin{array}{c}\text { Ketepatan } \\
\text { pasien }\end{array}$ & $\begin{array}{c}\text { Jumlah } \\
\text { pasien }\end{array}$ & $\begin{array}{c}\text { Persentase } \\
\text { (\%) }\end{array}$ \\
\hline $\begin{array}{l}\text { Tepat } \\
\text { pasien }\end{array}$ & 110 & $100 \%$ \\
\hline $\begin{array}{l}\text { Tidak tepat } \\
\text { pasien }\end{array}$ & 0 & 0 \\
\hline Total & $\mathbf{1 1 0}$ & $\mathbf{1 0 0 \%}$ \\
\hline
\end{tabular}

Berdasarkan hasil penelitian diatas, diperoleh bahwa penggunaan obat hipertensi berdasarkan tepat pasien sebanyak 110 pasien yaitu $100 \%$ tepat, karena dari semua obat yang diberikan pada pasien hipertensi sesuai dengan kondisi patologi dan fisiologi pasien, serta tidak adanya alergi dan tidak menimbulkan kontraindikasi pada pasien. 


\section{Tepat Indikasi}

Evaluasi ketepatan Indikasi adalah kesesuaian pemberian obat antara indikasi dengan diagnosa yang dilakukan dokter. Pemilihan obat dapat mengacu pada penegakan diagnosis, jika pemberian diagnosis tidak sesuai maka obat yang digunakan juga tidak akan memberi efek terapi yang diinginkan.

Tabel 4. Ketepatan Indikasi

\begin{tabular}{|c|c|c|}
\hline $\begin{array}{c}\text { Ketepatan } \\
\text { indikasi }\end{array}$ & $\begin{array}{c}\text { Jumlah } \\
\text { pasien }\end{array}$ & $\begin{array}{c}\text { Persentase } \\
\mathbf{( \% )}\end{array}$ \\
\hline $\begin{array}{c}\text { Tepat } \\
\text { indikasi }\end{array}$ & 110 & $100 \%$ \\
\hline $\begin{array}{c}\text { Tidak tepat } \\
\text { indikasi }\end{array}$ & 0 & 0 \\
\hline Total & $\mathbf{1 1 0}$ & $\mathbf{1 0 0 \%}$ \\
\hline
\end{tabular}

Berdasarkan hasil penelitian diatas, diperoleh bahwa penggunaan obat antihipertensi berdasarkan tepat indikasi sebanyak 110 pasien yaitu $100 \%$ tepat, karena obat antihipertensi ACEI, CCB, ARB dan Diuretik diberikan kepada pasien dengan diagnosis hipertensi tahap 1 dan tahap 2.

Hasil ini di perkuat dengan penelitian yang dilakukan oleh Eka Kartika Untari di Puskesmas Siantan Hilir Kota Pontianak tahun 2015 penelitian yang dilakukan terhadap 92 data rekam medik pasien hipertensi diperoleh nilai penggunaan obat berdasarkan tepat indikasi bernilai $100 \%$ tepat.

\section{Tepat Obat}

Evaluasi ketepatan obat yaitu apabila jenis obat yang dipilih berdasarkan pertimbangan manfaat dan resiko yang ditentukan dengan kesesuaian pemilihan golongan terapi baik tunggal maupun kombinasi dengan mempertimbangkan diagnosis serta tekanan darah yang tertulis dalam rekam medik dan membandingkan dengan literatur yang digunakan yaitu JNC VIII.

Tabel 5. Ketepatan Obat

\begin{tabular}{|c|c|c|}
\hline $\begin{array}{c}\text { Ketepatan } \\
\text { obat }\end{array}$ & $\begin{array}{c}\text { Jumlah } \\
\text { pasien }\end{array}$ & $\begin{array}{c}\text { Persentase } \\
\text { (\%) }\end{array}$ \\
\hline Tepat obat & 92 & $75,60 \%$ \\
\hline $\begin{array}{c}\text { Tidak tepat } \\
\text { obat }\end{array}$ & 18 & $24,40 \%$ \\
\hline Total & $\mathbf{1 1 0}$ & $\mathbf{1 0 0} \%$ \\
\hline
\end{tabular}

Berdasarkan hasil penelitian diatas, diperoleh bahwa penggunaan obat antihipertensi berdasarkan tepat obat sebanyak 92 pasien $(75,6 \%)$ tepat obat karena obat hipertensi yang diberikan sudah sesuai standar yang digunakan yaitu JNC VIII dan sebanyak 18 pasien $(24,4 \%)$ tidak tepat obat karena obat hipertensi yang diberikan tidak sesuai dengan standar yang digunakan.

Hasil tersebut di perkuat dengan penelitian yang dilakukan oleh Eka Kartika Untari di Puskesmas Siantan Hilir Pontianak tahun 2015 penelitian yang dilakukan terhadap 92 data rekam medik pasien hipertensi diperoleh nilai penggunaan obat berdasarkan tepat obat bernilai $(70,65 \%)$ tepat.

\section{Tepat Dosis}

Tepat dosis yaitu tepat dalam frekuensi pemberian, dosis yang diberikan dan jalur pemberian obat kepada pasien. 
Tabel 6. Ketepatan Dosis

\begin{tabular}{|c|c|c|}
\hline $\begin{array}{c}\text { Ketepatan } \\
\text { dosis }\end{array}$ & $\begin{array}{c}\text { Jumlah } \\
\text { pasien }\end{array}$ & $\begin{array}{c}\text { Persentase } \\
\mathbf{( \% )}\end{array}$ \\
\hline Tepat dosis & 110 & $100 \%$ \\
\hline $\begin{array}{c}\text { Tidak tepat } \\
\text { dosis }\end{array}$ & 0 & 0 \\
\hline Total & $\mathbf{1 1 0}$ & $\mathbf{1 0 0 \%}$ \\
\hline
\end{tabular}

Berdasarkan hasil penelitian diatas, diperoleh bahwa penggunaan obat antihipertensi berdasarkan tepat dosis sebanyak 110 pasien $100 \%$ tepat dosis, karena dosis obat antihipertensi yang diberikan sudah sesuai dengan range terapi obat antihipertensi berdasarkan Guidelines JNC VIII.

Hasil ini berbeda dengan penelitian sebelumnya yang dilakukan Eka Kartika Untari dan teman-teman di Puskesmas Siantan Hilir Kota Pontianak Tahun 2015 yang menyebutkan bahwa tepat dosis sebanyak $(98,91 \%)$ dari 92 sampel.

\section{KESIMPULAN DAN SARAN}

\section{Kesimpulan}

Berdasarkan dari penelitian yang telah dilakukan dapat disimpulkan sebagai berikut :

1. Karakteristik pada pasien hipertensi di RSU Wisma Rini Pringsewu Tahun 2019, berdasarkan Jenis kelamin diperoleh sebagian besar pasien perempuan $(55,46 \%)$, berdasarkan usia diperoleh paling banyak menyerang usia 46-55 tahun sebanyak (40\%). Berdasarkan tingkatan hipertensi diperoleh hipertensi tingkat 1 sebanyak $(65,45 \%)$ serta diperoleh hipertensi tingkat 2 sebanyak (34,55\%) dan obat yang digunakan terbanyak pasien hipertensi yaitu amlodipin (71\%)
2. Evaluasi penggunaan obat hipertensi pada pasien hipertensi di RSU Wisma Rini Pringsewu tahun 2019 diperoleh berdasarkan ketepatan pasien sebesar $100 \%$, ketepatan indikasi sebesar $100 \%$, ketepatan obat sebesar $75,6 \%$, dan ketepatan dosis sebesar $100 \%$.

\section{Saran}

Berdasarkan dari penelitian yang telah dilakukan dapat disarankan sebagai berikut: Perlu melakukan penelitian lebih lanjut tentang Evaluasi Penggunaan Obat Hipertensi Pada Pasien Hipertensi dengan metode prospektif.

\section{UCAPAN TERIMAKASIH}

Terimakasih kepada seluruh pihak Universitas Tulang Bawang Lampung dan Rumah Sakit Wisma Rini Pringsewu yang telah membantu dalam menyelesaikan penelitian.

\section{DAFTAR PUSTAKA}

1. Sari YNI. 2017. Berdamai dengan Hipertensi. Jakarta : Bumi Merdeka

2. Menkes. 2014. Infodatin Hipertensi. Jakarta : Pusat Data dan Informasi Kementerian Kesehatan RI.

3. Depkes. 2006. Pharmaceutical Care Untuk Penyakit Hipertensi. Jakarta : Direktorat Bina Farmasi dan Klinik.

4. Susilo Y. 2011. Cara Jitu Mengatasi Darah Tinggi. Yogyakarta : ANDI

5. WHO. 2020. Hipertension. diakses di http://www.who.int/news-room/factsheets/detail/hypertension

6. Riskesdas. 2018. Prevalensi Hipertensi di Indonesia. Jakarta : Kementrian Kesehat Republik Indonesia. 
7. Dinas Kesehatan Provinsi Lampung. Jumlah Kasus 10 Penyakit Terbanyak di Provinsi Lampung. Bandar Lampung: Badan Pusat Statistik Provinsi Lampung.

8. Sumawa PMR. dkk. Evaluasi Kerasionalan Penggunaan Obat Antihipertensi Pada Pasien Hipertensi Rawat Inap Di Rsup Prof. Dr. R. D. Kandou Manado Periode Januari-Juni 2014.

9. Untari EK. dkk. 2018. Evaluasi Rasionalitas Penggunaan Obat Antihipertensi di Puskesmas Siantan Hilir Kota Pontianak Tahun 2015.

10. Sukandar EYu. dkk. 2013. ISO Farmakoterapi Buku I. Jakarta Barat : ISFI.

11. Armstrong C. 2014. JNC 8 guidelines for the management of hypertension in adults. American Family Physician. 2014.

12. Syarif Amir, dkk. 2012 Farmakologi dan Terapi, Jakarta : Badan Penerbit FKUI.

13. Budi S, dkk. 2015. Hipertensi Manajemen Komprehensif. Surabaya : Airlangga University Press (AUP).

14. Tean Medical Mini Notes. 2017. Basic Pharmacology and Drug Notes. Makasar : MMN Publishing.

15. Menkes. Peraturan Menteri Kesehatan Republik Indonesia Nomor 72 Tahun 2016 Tentang Standar Pelayanan Kefarmasian di Rumah Sakit. Jakarta : Departemen Kesehatan Republik Indonesia.

16. Presiden, DPR. Undang-Undang Republik Indonesia Nomor 44 tahun 2009 tentang Rumah Sakit. Jakarta.

17. Menkes. Peraturan Menteri Kesehatan Republik Indonesia Nomor 340/MENKES/PER/III/2010 tentang Klasifikasi Rumah Sakit.
Jakarta : Departemen Kesehatan Republik Indonesia.

18. Menkes. Peraturan Menteri Kesehatan Republik Indonesia Nomor 4 tahun 2018 Tentang Kewajiban Rumah Sakit dan Kewajiban Pasien. Jakarta : Departemen Kesehatan Republik Indonesia.

19. Siregar Charles J. Farmasi Rumah Sakit: Teori dan Penerpan. In: Buku Kedokteran EGC. 2004.

20. Rusli. 2016. Modul Farmasi Rumah Sakit dan Klinik. Jakarta: Kementerian Kesehatan Republik Indonesia.

21. Menkes. Peraturan menteri kesehatan Republik Indonesia Nomor 269/Menkes/Per/ll//2008 Tentang Rekam Medik. Jakarta: Departemen Kesehatan Republik Indonesia.

22. Notoatmodjo S. 2010. Metodelogi Penelitian Kesehatan. Jakarta: Rineka Cipta.

23. Profil Rumah Sakit Wisma Rini Pringsewu Tahun 2019

24. Pedoman Teknis dan Tata Laksana Penyakit Hipertensi, Direktorat Pengendalian Penyakit Tidak Menular Direktorat Jendral PP \& PL Departemen Kesehatan RI Tahun 2006.

25. Laura A, Darmayanti, Hasni D. 2018. Evaluasi Penggunaan Obat Antihipertensi di Puskesmas Ikur Koto Kota Padang Periode 2018.

26. Farmakope Indonesia Edisi III. Departemen Kesehatan Republik Indonesia, Jakarta. Tahun 1979. 